\title{
A call to arms against an enemy yet unknown
}

\author{
Katie S. Nason, MD, MPH
}

\footnotetext{
From the Division of Thoracic and Foregut Surgery, Department of Cardiothoracic Surgery, University of Pittsburgh, Pittsburgh, Pa.

Dr Nason's work is supported by award No. K07CA151613 from the National Cancer Institute. The content is solely the responsibility of the authors and does not necessarily represent the official views of the National Cancer Institute or the National Institutes of Health.

Disclosures: Author has nothing to disclose with regard to commercial support.

Received for publication Sept 3, 2015; accepted for publication Sept 3, 2015.

Address for reprints: Katie S. Nason, MD, MPH, Division of Thoracic and Foregut Surgery, Department of Cardiothoracic Surgery, University of Pittsburgh, 5200 Centre Ave, Suite 715, Shadyside Medical Building, Pittsburgh, PA 15232 (E-mail: nasonks@upmc.edu).

J Thorac Cardiovasc Surg 2015;150:1506-7

$0022-5223 / \$ 36.00$

Copyright (c) 2015 by The American Association for Thoracic Surgery

http://dx.doi.org/10.1016/j.jtcvs.2015.09.043
}

In the article, "Unexpected readmission after lung cancer surgery: A benign event?" in this issue of the Journal, Puri and colleagues ${ }^{1}$ seek to identify risk factors for readmission after lung cancer surgery using data from the $\mathrm{Na}$ tional Cancer Data Base, which is jointly sponsored by the American College of Surgeons and the American Cancer Society. The incidence, potential predictors, and implications of unanticipated early postoperative readmission after lung resection for non-small cell lung cancer were examined in 129,893 patients; 5624 (4.3\%) had unanticipated early readmission (ie, within 30 days of resection) after initial discharge. After controlling for potential confounders, the data show that increasing age, increasing Charlson-Deyo comorbidity score, exposure to preoperative radiation, pneumonectomy (vs sublobar resection), larger tumor size, and longer length of hospital stay at the index operation are all risk factors for readmission. Protective factors identified included higher annual income $(>\$ 35,000)$ and treatment in an academic center. Patients who are readmitted have increased rates of 30- and 90-day mortality and worse overall survival compared with propensity-score matched patients who were not readmitted.

Puri and colleagues have accomplished a timely analysis of a topic of extreme importance to thoracic surgeons in an era where reimbursement is being tied to quality metrics that include unexpected readmission. The strengths of the study include the very large number of patients and events available for the analysis and the use of propensity-score matching to balance the baseline characteristics of the patients. The study is consistent with the published literature on the topic: Using data from the Surveillance Epidemiology and End Results-Medicare registry (2006-2011), $\mathrm{Hu}$ and colleagues ${ }^{2}$ evaluated 11,432 patients discharged alive after lung resection for lung cancer and noted a 6-fold increase in 90-day mortality for readmitted patients. Factors associated with readmission included resection type; age; prior induction chemoradiation; preoperative

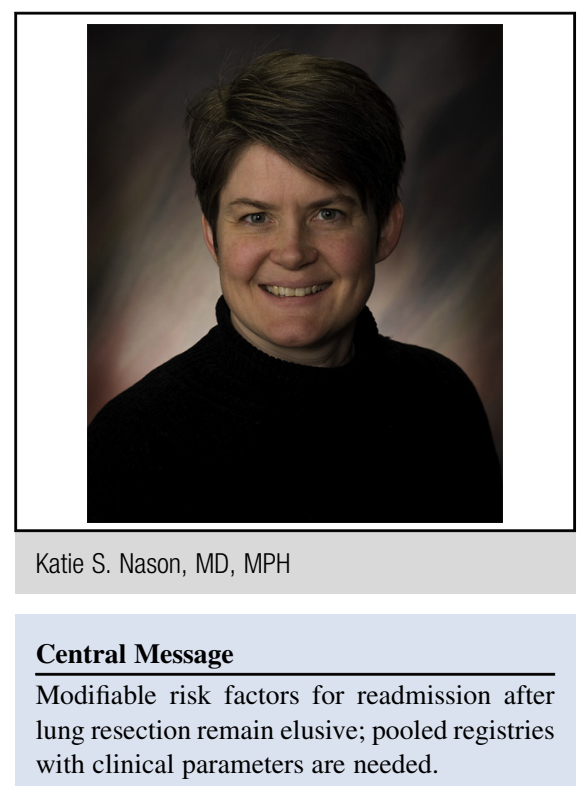

See Article page 1496.

comorbidities, including chronic obstructive pulmonary disease and congestive heart failure; and surgery in regions with low population density. Notably, they found that more than a quarter of readmissions were to other facilities. Taken together with the study by $\mathrm{Hu}$ and colleagues, ${ }^{2}$ and given the comprehensiveness of the data available in the National Cancer Data Base, which includes approximately $70 \%$ of all new cancer patients diagnosed in the United States and Puerto Rico, the data from the current study should leave thoracic surgeons ready to charge at the problem of excessive readmissions and consequent monetary penalties at each of our institutions.

Unfortunately, this is not the case. Although the analysis arms us with numerous factors associated with readmission, the true enemy has yet to be elucidated. Despite the very large number of patients and the tremendous power for indepth data analysis provided by the National Cancer Data Base, the discriminatory accuracy of the model is only $60 \%$. In general, the poor discriminatory accuracy of the model indicates that important predictors are unaccounted for in the analysis. Although extremely well executed, the results of this study reflect the limitations of most largescale databases. Clinically relevant predictors are frequently lacking, including underlying pulmonary function, 3,4 approach to operation (open vs minimally invasive), ${ }^{4,5}$ and detailed comorbidities. ${ }^{3,4}$ These and other predictors have been shown to be associated with 
postoperative mortality and long-term survival after resection for lung cancer. The National Cancer Data Base also lacks relevant data regarding the complications experienced during the index operation, which are strongly associated with longer hospital stay and increased 30- and 90-day mortality. As a result, despite using sophisticated statistical analyses with propensity-matched analysis and segregation into risk strata, our understanding of the specific influence of readmission on these outcomes remains incomplete because the present analysis and others to date do not account for these critical risk factors.

Moving forward, it is imperative that thoracic surgeons heed the call to arms issued by Puri and colleagues to work together through pooled registries to identify a targetable enemy. These registries must include expansive and comprehensive data on patients, including pulmonary function, comorbid diseases, and cardiac parameters, and all other described predictors of adverse postoperative outcomes. Through combined efforts, we must continue to refine our understanding of modifiable risk factors for adverse outcomes and develop comprehensive and costeffective measures that will reduce complications and optimize outcomes after surgical resection for lung cancer.

\section{References}

1. Puri P, Patel AP, Crabtree TD, Bell JM, Broderick SR, Kreisel D, et al. Unexpected readmission after lung cancer surgery: a benign event? J Thorac Cardiovasc Surg 2015;150:1496-505.e1-5.

2. Hu Y, McMurry TL, Isbell JM, Stukenborg GJ, Kozower BD. Readmission after lung cancer resection is associated with a 6-fold increase in 90-day postoperative mortality. J Thorac Cardiovasc Surg. 2014;148:2261-7.e1.

3. Friedel G, Fritz P, Goletz S, Kristen R, Brinkman F, Dierkesmann R, et al. Postoperative survival of lung cancer patients: are there predictors beyond TNM? Anticancer Res. 2013;33:1609-19.

4. Bernard A, Rivera C, Pages PB, Falcoz PE, Vicaut E, Dahan M. Risk model of inhospital mortality after pulmonary resection for cancer: a national database of the French Society of Thoracic and Cardiovascular Surgery (Epithor). J Thorac Cardiovasc Surg. 2011;141:449-58.

5. Boffa DJ, Dhamija A, Kosinski AS, Kim AW, Detterbeck FC, Mitchell JD, et al Fewer complications result from a video-assisted approach to anatomic resection of clinical stage I lung cancer. J Thorac Cardiovasc Surg. 2014;148:637-43. 